Available online at: http://journal.unj.ac.id

Jurnal

Pensil

Pendidikan Teknik Sipil

Journal homepage: http://journal.unj.ac.id/unj/index.php/ipensil/index

\title{
MODELLING 2-D PONDASI JEMBATAN BERDASARKAN PEMBEBANAN DAN LETAK POSISI BATUAN ' $\mathrm{X}$ '
}

\section{MODELING 2-D FOUNDATION OF BRIDGES BASED ON LOADING AND LOCATED ROCK POSITION ' $X$ ' WITH ON GRAPHIC USER INTERFACE PROGRAM BASED ON MATLAB}

\author{
Risal Ardiansyab $P^{1}$, Fachri Almawali $A^{2}$, Widya Utama \\ Institut Teknologi Sepuluh Nopember \\ risalsyahputra66@gmail.com
}
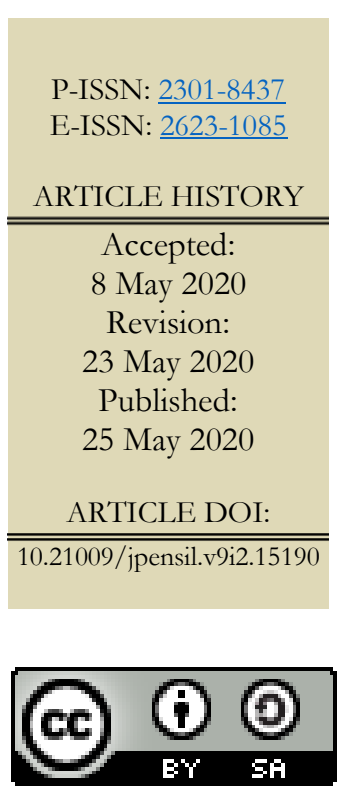

Jurnal Pensil : Pendidikan Teknik Sipil is licensed under a Creative Commons Attribution-ShareAlike. 4.0 International License (CC BY-SA 4.0).

\begin{abstract}
Abstrak
Penelitian ini berisi tentang analisis pembebanan dan posisi batuan pada pondasi jembatan berdasarkan respon batuan terhadap gaya yang akan diuji dengan program "Graphic User Interface (GUI)" menggunakan MATLAB. Penelitian ini juga menjelaskan rencana pemodelan pondasi jembatan berdasarkan gaya-gaya yang diuji di atas batuan bernama ' $X$ '. Gaya respon yang dibahas dalam penelitian ini adalah gaya normal, gaya lintang dan gaya momen. Data diolah menggunakan software MATLAB, kemudian disajikan dalam bentuk tabel, grafik dan grafik permodelan 2D yang menunjukkan pembebanan dan posisi batuan yang sesuai dengan pondasi jembatan. Setelah mendapatkan data batuan 'X', data tersebut kemudian diolah menggunakan program Graphic User Interface melalui program grafik gaya momen, gaya normal dan gaya lintang dan nantinya hasil yang diperoleh dapat dipertimbangkan untuk pemodelan pembebanan dan letak posisi batuan ' $\mathrm{X}$ '. melalui pengolahan data yang telah dilakukan, gaya normal diperoleh sebesar nol, gaya lintang sekitar (0 hingga 8) $\mathrm{N}$ dan gaya momen sekita (-60 hingga 0) $\mathrm{N}$. Berdasarkan perhitungan tersebut diketahui bahwa ' $\mathrm{X}$ ' batuan dapat dimodelkan dalam bentuk persegi panjang dengan pusat gravitasi merata di tengah. Dan model yang digunakan adalah placement pinch karena tidak memiliki nilai translasi dan rotasi sehingga batuan ' $\mathrm{X}$ ' cocok untuk dijadikan pondasi jembatan.
\end{abstract}

Kata kunci: gaya geser, gaya momen, gaya normal, GUI, pemodelan

Abstract
This paper contains an analysis of the loading and the position of rock in the bridge
foundation based on the rock's response to the force that will be tested with
"Graphic User Interface (GUI)" program using MATLAB. This paper also
explains the preparation of bridge foundation modeling based on the forces tested on
the rock named ' $x$ '. The response forces discussed in this paper are normal force,
latitude force and moment force. The data is processed using MATLAB software
and then presented in the form of tables, graphs and $2 D$ modeling that shows the


loading and the position of rocks correspondence to the bridge foundation. After obtaining the rock's ' $x$ ' data, the data is then processed using Graphic User Interface program, through the program moment force graphs, normal force graphs, latitude graphs can be obtained which later these results can be considered for modeling the loading and the position of the rock's ' $x$ '. Through the data processing that has been done, zero normal force is obtained, and the latitude has a value of about (0 to 8) N and the moment force of about (-60 to 0) N. Based on these calculations it was found that the rock's ' $x$ ' can be modeled by arranging it rectangle with center of gravity evenly distributed at the center. And the model that are used is the placement pinch model because it does not have translational and rotational values so that the rock ' $x$ ' is suitable to be the bridge's foundation.

Keywords: shear forces, bending moment, normal forces, GUI, modelling

\section{Pendahuluan}

Kesalahan saat melakukan perhitungan bukanlah hal yang jarang terjadi apalagi bagi orang yang kurang berpengalaman terhadapnya. Dimasa sekarang ini banyak alternatif yang dapat dilakukan untuk mengurang kesalahan dalam perhitungan tersebut, salah satunya adalah dengan menggunakan bantuan dari perangkat lunak. Meski begitu, tidak semua masalah perhitungan memiliki perangkat lunaknya dikhususkan untuk menyelesaikannya. Pembuatan inovasi perangkat lunak atau program yang baru (berdiri sendiri) tentunya akan memerlukan waktu yang lama, maka dibuatlah program sederhana yang dikhususkan untuk modeling 2-D pondasi jembatan dengan maksud dalam segi perhitungannya.

Dalam perencanaan pembuatan jembatan, diperlukan perhitungan yang akurat agar tidak terjadi kesalahan pada saat tahap pembangunannya, dalam perhitungan tersebut beberapa hal yang perlu dihitung untuk pondasi tersebut adalah tekanan tanah, beban mati, beban hidup serta gayagaya lain yang disusun secara terstruktur mengikuti proses perhitungan sesuai dengan pedoman yang digunakan. Bagian paling bawah dari suatu konstruksi bangunan adalah pondasi sehingga perhitungan dalam pembuatan pondasi jembatan sangat penting untuk menentukan model pondasi jembatan. Pada penelitian ini akan dibahas pengaruh pembebanan dan posisi peletakan batuan dan hasil perhitungan nantinya akan digunakan sebagai masukan dalam penyiapan gambar rencana, yang merupakan salah satu komponen dari produk perencanaan teknis jembatan. Beban dalam hal ini dibagai menjadi dua, yaitu : Beban Mati dan Hidup. Beban mati merupakan berat individual seluruh bangunan, baik struktur maupun non struktur yang bekerja pada bangunan atau pondasi ini. Beban mati sangat tergantung dari dimensi serta berat jenis struktur yang digunakan dalam pembuatan jembatan (Fahmi, 2013). Beban hidup merujuk pada berat diluar beban mati (berat tambahan) yang bekerja pada suatu waktu tertentu, yang mengartikan beban tersebut dapat berkerja secara terus menerus dan sementara. Peraturan Pembebanan Indonesia dapat dijadikan referensi untuk melihat besarnya beban hidup oleh peruntukan bangunan, dengan harga minimum. (Fahmi, 2013).

Semua bangunan (konstruksi) terletak di atas tumpuan/perletakan. Fungsi tumpuan sendiri adalah untuk menyalurkan gaya-gaya yang bekerja pada konstruksi baik gaya luar maupun berat konstruksi itu sendiri ke bagian bawah. Hal tersebut menyebabkan adanya reaksi-reaksi yang mengimbangi gaya-gaya luar dan berat 
konstruksi. Tumpuan tadi dapat menahan gaya dalam arah vertikal (Rv), arah horizontal $(\mathrm{Rh})$, serta gaya momen $(\mathrm{Mx})$. Tumpuan jepit yang tidak mengalami rotasi dan translasi disebut tumpuan kaku (rigid). Tumpuan jepit tersebut juga dapat menahan gaya ke segala arah dan dapat menahan gaya momen. Hal tersebut berarti tumpuan jepit mempunyai tiga reaksi yaitu reaksi vertikal $\mathrm{RV}$, reaksi horisontal $\mathrm{RH}$ dan reaksi momen RM (Soemono, 1985). Selain itu, terdapat berbagai gaya, seperti Shear forces diagram (Gaya lintang) adalah gaya yang disusun tegak lurus dengan sumbu batang. Sebelum melakukan perhitungan, nilai negatif dan positif perlu kesepatakan terlebih dahulu. Pada penelitian ini Gaya lintang (SFD) positif bila perputaran gaya yang bekerja searah dengan jarum jam, dan tegak lurus dengan sumbu batang yang menerima gaya lintang. Sebaliknya, bila perputaran gayanya berlawanan arah dengan jarum jam, maka SFD negatif dan sejajar dengan sumbu batang, (Ma'arif, 2012).

Gaya Normal merupakan gaya yang memiliki garis kerja yang sejajar dengan sumbu batang. Pada penelitian ini, nilai gaya normal akan positif apabila gaya tersebut merupakan gaya normal tarik dan nilainya Negatif bila jenisnya adalah gaya normal tekan (Ma'arif, 2012). Kemudian diperlukan Momen (Bending Moment Diagram/BMD) adalah hasil kali antara gaya dengan jarak (jarak garis lurus terhadap garis kerjanya). Bidang momen memiliki tanda positif jika yang mengalami tarikan adalah bagian bawah.

Pada penelitian ini Bidang momen bernilai positif bila diarsir tegak lurus sumbu batang yang mengalami momen. Tetapi, bila yang mengalami tarikan pada bagian atas atau diluar bidang momen, maka tandanya negatif. Bidang momen negatif diarsir sejajar dengan sumbu batang. Perjanjian penggunaan tanda perlu diperhatikan dengan teliti agar tidak terjadi kesalahpahaman (Ma'arif, 2012).
Kemudian terdapat bagian pondasi yang sering disebut sebagai bagian bawah dari suatu konstruksi bangunan. Pondasi pada penelitian ini merujuk pada pondasi dengan fungsi untuk meneruskan beban dari konstruksi ke lapisan tanah yang berada di bawah pondasi dengan tidak melampaui kekuatan tanah di bawah pondasi. Apabila besar kekuatan tanah dilampaui oleh beban, maka akan terjadi keruntuhan, kedua hal tersebut akan menyebabkan kerusakkan pada konstruksi yang berada di atas pondasi (Departemen, 2007).

Berdasarkan berbagai komponen yang telah disebutkan diperlukan analisis pemuatan dan posisi batu di pondasi jembatan berdasarkan respons batu terhadap gaya yang akan diuji dengan program "Graphic User Interface (GUI)" menggunakan MATLAB. Analisis ini berguna sebagai acuan modelling-2D pondasi jembatan berdasarkan pembebanan dan letak posisi batuan ' $\mathrm{x}$ '.

\section{Metode Penelitian}

Metode penelitian ini adalah modelling2D menggunakan software Graphic User Interface berbasis MATLAB. Pada penelitian ini diperlukan Data Paper Acuan yang diperlukan untuk mengolah script MATLAB. Hal tersebut berguna untuk memprogram input rumus perhitungan pada setiap data untuk diplot, sehingga didapatkan grafik gaya momen, grafik gaya normal, grafik gaya lintang sebagai pertimbangan untuk menggunakan batuan ' $x$ ' dalam permodelan pondasi jembatan.

\section{Hasil Penelitian dan Pembahasan}

Setelah didapatkannya data beban merata, beban terpusat, gaya normal, gaya lintang, gaya momen, ukuran batuan $\mathrm{x}$, maka dibuatlah script MATLAB untuk pengolahan data mentah tersebut, hal pertama yang dilakukan dalam pembuatan script adalah membuat flowchart langkah kerja. 


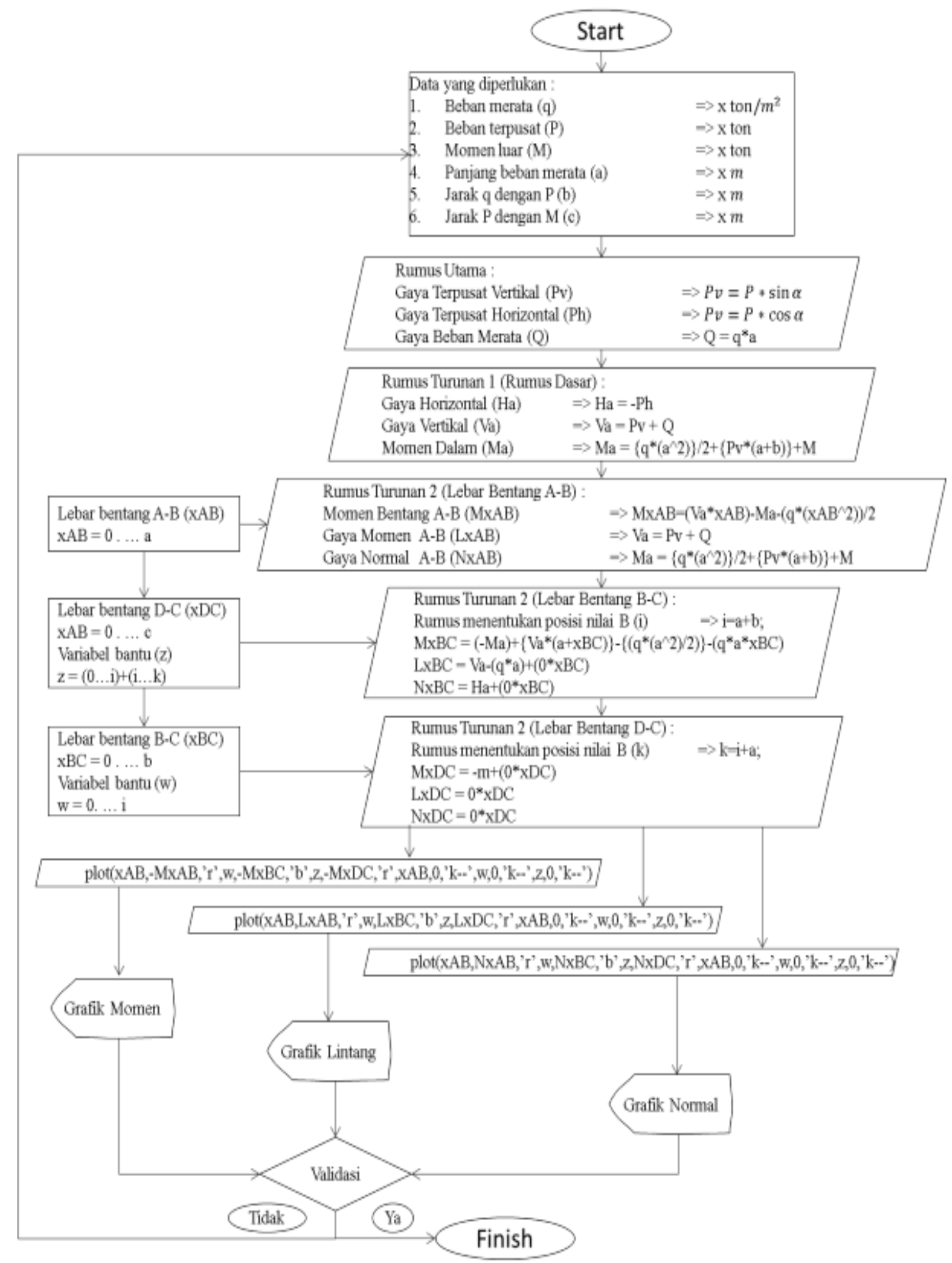

Gambar 1. Flowchart langkah kerja 
Pertama adalah mempersiapkan data yang diperlukan yaitu beban merata, beban terpusat, momen luar, panjang beban merata, jarak beban merata dengan beban terpusat, jarak beban terpusat dengan momen luar. Mengacu pada rumus utama, dilakukan penurunan rumus sehingga didapatkan rumus dasar yang selanjutnya diturunkan kembali sehingga didapatkan untuk perhitungan pada ketiga lebar bentang (A-B, B-C, D-C) setelah memasukkan lebar ketiga bentang. Setelah dilakukannya perhitungan pada ketiga bentang maka dilakukan plotting untuk mendapatkan grafik gaya momen, lintang, dan normal dengan bantuan software MATLAB, lalu dilakukan validasi pada hasil pengolahan yang dilakukan agar memiliki komponen ang ada pada data awal.

Berdasarkan percobaan ini maka diperoleh beberapa data gaya lintang, gaya momen dan gaya normal sebagai berikut :

Tabel 1. Pembentangan M, L dan N

\begin{tabular}{|c|c|c|c|}
\hline $\begin{array}{c}\text { A-B } \\
(0 \leq x \leq 2)\end{array}$ & $\begin{array}{c}M x=8 x \\
-60\end{array}$ & $\mathrm{Lx}=8$ & $N x=0$ \\
\hline 0 & $\mathrm{M}_{0}=-60$ & $\mathrm{~L}_{0}=8$ & $\mathrm{~N}_{0}=0$ \\
\hline 1 & $\mathrm{M}_{0}=-56$ & $\mathrm{~L}_{1}=8$ & $\mathrm{~N}_{1}=0$ \\
\hline 2 & $\mathrm{M}_{0}=-44$ & $\mathrm{~L}_{2}=8$ & $\mathrm{~N}_{2}=0$ \\
\hline $\begin{array}{c}\text { B-C } \\
(0 \leq x \leq 3)\end{array}$ & $\begin{array}{c}M x=8 x \\
-40\end{array}$ & $\mathrm{Lx}=8$ & $N x=0$ \\
\hline 0 & $\mathrm{M}_{0}=-40$ & $\mathrm{~L}_{0}=8$ & $\mathrm{~N}_{0}=0$ \\
\hline 1 & $\mathrm{M}_{1}=-32$ & $\mathrm{~L}_{1}=8$ & $\mathrm{~N}_{1}=0$ \\
\hline 2 & $\mathrm{M}_{2}=-24$ & $\mathrm{~L}_{2}=8$ & $\mathrm{~N}_{2}=0$ \\
\hline 3 & $\mathrm{M}_{3}=-16$ & $\mathrm{~L}_{3}=8$ & $\mathrm{~N}_{3}=0$ \\
\hline $\begin{array}{c}\text { C-D } \\
(0 \leq x \leq 4)\end{array}$ & $\begin{array}{l}M x=-x^{2} \\
+8 x-16\end{array}$ & $L x=8-2 x$ & $N x=0$ \\
\hline 0 & $\mathrm{M}_{0}=-16$ & $\mathrm{~L}_{0}=8$ & $\mathrm{~N}_{0}=0$ \\
\hline 1 & $\mathrm{M}_{1}=-9$ & $\mathrm{~L}_{1}=6$ & $\mathrm{~N}_{1}=0$ \\
\hline 2 & $\mathrm{M}_{2}=-4$ & $\mathrm{~L}_{2}=4$ & $\mathrm{~N}_{2}=0$ \\
\hline 3 & $\mathrm{M}_{3}=-1$ & $\mathrm{~L}_{3}=2$ & $\mathrm{~N}_{3}=0$ \\
\hline 4 & $\mathrm{M}_{4}=0$ & $\mathrm{~L}_{4}=0$ & $\mathrm{~N}_{4}=0$ \\
\hline
\end{tabular}

Keterangan :

$$
\begin{array}{ll}
\mathrm{M} & =\text { gaya momen } \\
\mathrm{L} & =\text { gaya lintang } \\
\mathrm{N} & =\text { gaya normal }
\end{array}
$$

Berdasarkan percobaan ini maka diperoleh hasil data dari gaya lintang, gaya momen dan gaya normal sebagai berikut :

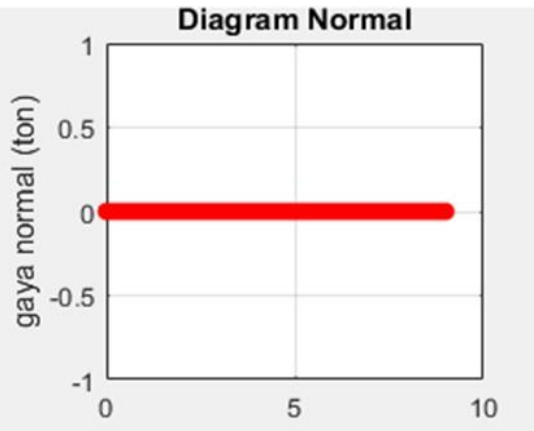

Gambar 2. Diagram gaya normal

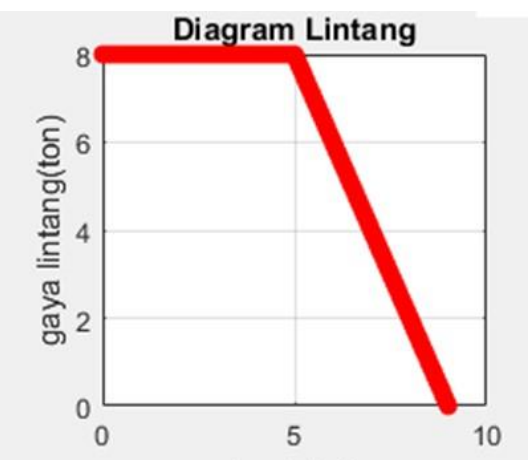

Gambar 3. Diagram gaya lintang

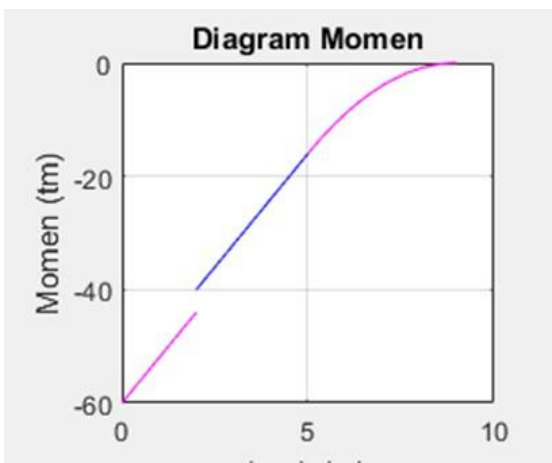

Gambar 4. Diagram gaya momen

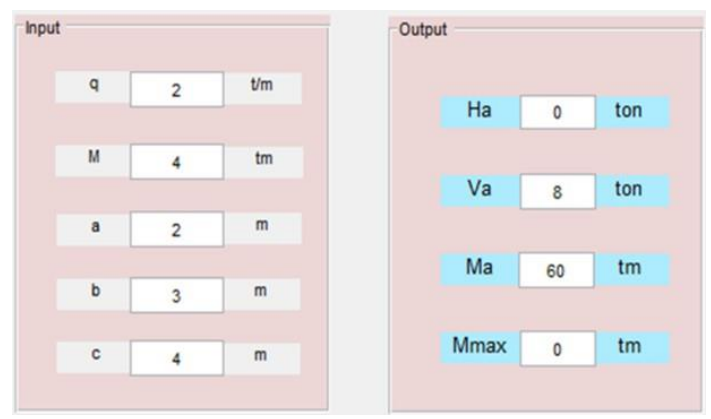

Gambar 5. Perhitungan Modelling berbasis MATLAB 


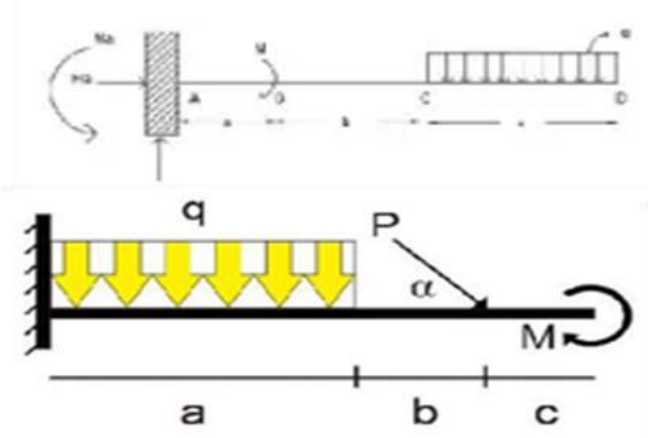

Gambar 6. Pemodelan 2D dengan MATLAB

Berdasarkan data dan hasil modelling dengan menggunakan software MATLAB, dapat diketahui pembebanan dan posisi susunan batuan yang sesuai dengan pondasi jembatan berdasarkan data batu ' $\mathrm{x}$ '. Berdasarkan pada perhitungan, gaya normal didapatkan nilai nol, sedangkan gaya lintang memiliki nilai sekitar (0 sampai 8) $\mathrm{N}$ dan gaya momen sekitar (-60 sampai 0) N. Berdasarkan gambar 2 gaya normal menunjukkan nilai konstan sehingga kecepatan pada batu ' $x$ ' bernilai nol $(\Delta V=0)$. Sedangkan pada gambar 3 gaya lintang mengalami penurunan nilai pada waktu ke 5 hingga waktu ke 10 dan pada gambar 4 gaya momen bernilai negatif hingga bernilai nol pada saat waktu $(t=0)$ sampai $(t=10)$, sehingga memiliki nilai percepatan nol $(\Delta \alpha$ $=0)$. Sehingga berdasarkan data batu ' $\mathrm{x}$ ' tersebut, batu tersebut tidak memiliki nilai translasi dan rotasi, yang mengakibatkan batu ' $x$ ' ini sesuai jika dilakukan perletakan dengan model perletakan jepit karena perletakan ini memiliki 3 gaya reaksi, gaya reaksi dalam arah horizontal, gaya reaksi dalam arah vertikal, dan gaya momen, sehingga perletakan ini dapat menahan gerak translasi dalam segala arah dan rotasi sehingga sesuai menjadi pondasi jembatan (Hady, 2013).

Selain mengetahui posisi perletakan batuan dalam pondasi jembatan juga perlu diketahui model pembebanan batuan tersebut. Untuk mengetahui distribusi pembebanan, harus mengetahui luasan beban merata pada tiap titik berat susunan batuan jika disusun berbentuk persegi, segitiga maupun bentuk lainnya. Selanjutnya berdasarkan gambar 6 menunjukkan bahwa batu ' $\mathrm{x}$ ' ini sesuai dengan bentuk persegi panjang untuk pembebanan. Dan dalam pembebanan sendiri harus memiliki ukuran yang sesuai. Berdasarkan gambar 6, dikarenakan modelling-nya berbentuk persegi panjang maka titik berat pada batuan tersebut terdapat pada titik saat di setengah dari lebar dan setengah panjang seperti yang ditunjukkan pada gambar 7 .

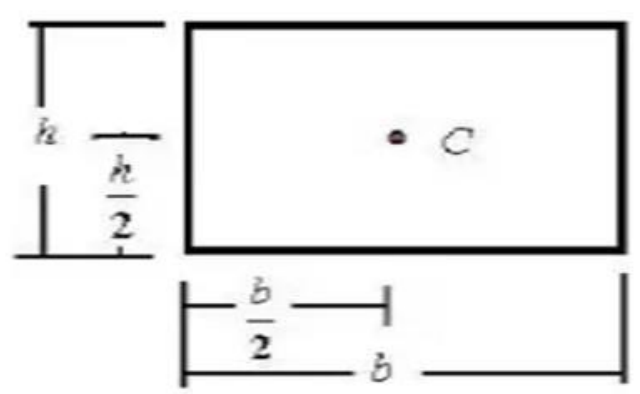

Gambar 7. Titik berat pada ukuran

Batuan tersebut berbentuk persegi panjang, sehingga berdasarkan hal-hal tersebut batu ' $\mathrm{x}$ ' ini sesuai menjadi pondasi jembatan jika batu diletakan dengan modelling jepit dan disusun secara persegi panjang. Dan berdasarkan analisis dapat diketahui model jembatan yang dapat dibuat dengan batu ' $x$ ' tersebut pada gambar 8 yang dapat digunakan dalam rencana pembuatan pondasi jembatan.

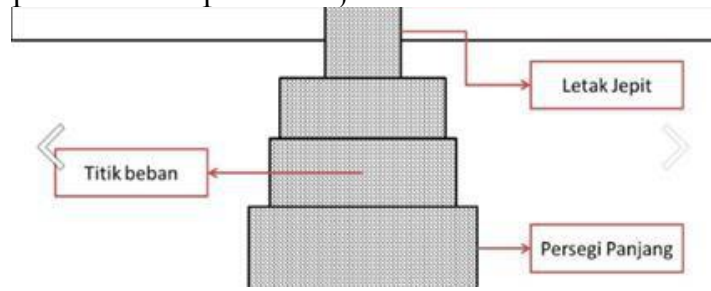

Gambar 8. Penyiapan gambar rencana pondasi jembatan

\section{Simpulan}

Berdasarkan analisis yang telah dilakukan didapatkan bahwa batu ' $\mathrm{x}$ ' dapat dimodelkan dengan disusun secara persegi panjang dengan titik berat yang merata di pusat. Dalam studi ini, digunakan perletakan dengan model jepit dikarenakan model jepit tidak memiliki nilai translasi dan 
rotasi sehingga batu ' $\mathrm{x}$ ' ini sesuai menjadi pondasi jembatan. Untuk meningkatkan keakuratan dari hasil modelling, pondasi jembatan sebaiknya dilakukan dalam 3-D dan batuan yang digunakan tidak hanya satu jenis saja agar dapat dibandingkan.

\section{Daftar Pustaka}

Departemen, P. U. (2007). Pelatiahan Abli Perencanaan Teknis Jembatan Bridge Design Engineer). Jakarta: Pusat Pembinaan Kompetisi dan Pelatihan Konstruksi.
Fahmi, A. (2013). Perencanaan Struktur Bangunan Sipil. Malang: Universitas Negeri Malang.

Hady. (2013). GUI Matlab Untuk Membuat Grafik Fungsi. Yogyakarta: Universitas Negeri Yogyakarta.
Ma'arif, F. (2012). e-Learning MEKANIKA TEKNIK 01. Yogyakarta: Universitas Negeri Yogyakarta.

Soemono, I. (1985). Statistika 1. Bandung: Institut Teknologi Bandung. 